\title{
Effects of Reinnervation of the Triceps Brachii on Joint Kinematics and Electromyographic Patterns of the Feline Forelimb during Level and Upslope Walking
}

\author{
Beven P. Livingston T. Richard Nichols \\ Emory University, Atlanta, Ga., USA
}

\section{Key Words}

Electromyographic patterns · Forelimb - Joint kinematics · Locomotion · Nerve injury

\begin{abstract}
Nerve injury in the hindlimb of the cat results in locomotor changes, yet these findings have not been explored in a more multifunctional forelimb. Kinematics and muscle activity of the shoulder and elbow during level and upslope locomotion following reinnervation of the feline long head of the triceps brachii (TLo) were evaluated (1) during paralysis [none to minimum motor activity (short-term effects)] and (2) after the motor function was recovered but the proprioceptive feedback was permanently disrupted (long-term effects). The step cycle was examined in three walking conditions: level (0\%), $25 \%$ grade ( $14^{\circ}$ upslope) and $50 \%$ grade (26.6 $6^{\circ}$ upslope). Measurements were taken prior to and at three time points ( 2 weeks, 1 month and $12+$ months) after transecting and suturing the radial nerve of TLo. There was less of a yield (increased flexion) at the elbow joint and more extensor activity during elbow flexion during stance (E2) as the grade of walking increased. Substantial short-term effects were observed at the elbow joint (increased flexion during E2) as well as increased motor activity by the synergistic elbow extensors, and greater shoulder extension at paw contact, leading to altered interjoint coordination dur-
\end{abstract}

ing stance. Forelimb shoulder and elbow kinematics during level and upslope locomotion progressed back to baseline at 12 months. The short-term effects can be explained by both mechanical and neural factors that are altered by the functional elimination of the TLo. Full recovery of the forelimb kinematics during level and upslope walking suggests that the proprioceptive length feedback loss is compensated by other sensory sources or altered central drive.

(c) 2015 S. Karger AG, Basel

\section{Abbreviations used in this paper}

Bi biceps brachii

$\mathrm{Br} \quad$ brachialis

$\mathrm{ClB} \quad$ cleidobrachialis

E1 first extension of the elbow

E2 elbow flexion during stance (yield)

E3 second elbow extension

EMG electromyographic

P1mo 1 month after surgery

P12+mos >12 months after surgery

P2wks 2 weeks after surgery

PC paw contact

PO paw off

TLa lateral head of the triceps

TLo long head of the triceps brachii

TM medial head of the triceps

\section{KARGER}

E-Mail karger@karger.com

www.karger.com/cto
(C) 2015 S. Karger AG, Basel

$1422-6405 / 15 / 1996-0405 \$ 39.50 / 0$
Beven P. Livingston

University of North Florida

1 UNF Drive

Jacksonville, FL 32224-7699 (USA)

E-Mail b.livingston@unf.edu 


\section{Introduction}

Reinnervation is a surgical procedure in which a muscle nerve is transected and then resutured in order to mimic a nerve lesion caused by trauma followed by subsequent surgical repair. This procedure involves an initial paralytic, or denervation, stage (no muscle activity) followed by a prolonged recovery phase, in which the regenerating motoneuron axons return to the motor endplates in the reinnervated muscle [Sanes and Lichtman, 1999]. Electromyographic (EMG) activity is restored in the reinnervated muscle [Gregor et al., 2003]; however, reinnervation results in a long-term (up to 36 months after surgery) loss of length feedback and the attenuation of force feedback in the corresponding muscles of the cat [Cope et al., 1991; Cope and Clark, 1993; Cope et al., 1994]. This method can be used to study the role of feedback during locomotion and the adaptive capacity of the animal to the paralysis of a muscle or the loss of length feedback. Several studies have documented neuromuscular recovery at muscle and spinal cord level in the hindlimb after reinnervation [Gordon and Stein, 1982a, b; Foehring et al., 1986; Alvarez et al., 2011; Bullinger et al., 2011] and the adaptations which occur in joint kinematics [Abelew et al., 2000; Maas et al., 2007], but very little is known about the effects of reinnervation on the forelimb. The quadruped forelimb is used for reaching as well as locomotion and therefore has a larger behavioral repertoire than the hindlimb. This attribute could be associated with a larger capacity for adaptation. Joint kinematics and neuromuscular activity are output variables of the motor system, thus monitoring them is a very important clinical assessment tool during the functional recovery after peripheral nerve injury or neurotomy [Simon et al., 1978; Lehmann et al., 1985].

The redundant nature of the musculoskeletal systems implies that specific tasks can be executed with a variety of muscular activation patterns or synergies. However, cyclical movements are performed in a very stereotypical way. Similar patterns of muscular coordination have been observed both within and across subjects during movement tasks, such a quadruped locomotion [English, 1978; Walmsley et al., 1978; Hodgson, 1983; Herzog et al., 1993]. A fundamental issue in the neuromuscular control of movement and the goal of functional rehabilitation is the extent to which the nervous system is capable of compensating for the loss of a muscle across varied tasks with different mechanical demands.

Forelimb upslope locomotion introduces different mechanical loads, and provides a challenge to an inherently unstable glenohumeral joint and the biarticular muscles that span the shoulder and elbow joints. During level quadruped locomotion, the vertical ground reaction forces were higher for the forelimb than the hindlimb [Prilutsky et al., 2005] and are consistent with the literature, which suggests this is because the center of mass of the cat is closer to the forelimb [Manter, 1938; Alexander, 1980; Pandy et al., 1988]. Also, because of the higher forelimb forces, the peak joint moments were also greater for the forelimb versus the hindlimb. Among the joints of the forelimb, the elbow contributes the most to power generation and propulsion during stance as compared to the ankle joint in the hindlimb [Prilutsky et al., 2005]. Although there have been no reports of forelimb kinematic or kinetic studies of the feline forelimb during graded locomotion reported in the literature, studies by researchers in the cat hindlimb [Gregor et al., 2001; Kaya et al., 2003, 2005] showed that the ankle extensor moments were greater for upslope walking than during level or downhill walking. Therefore, it may be hypothesized that upslope locomotion provides a greater challenge to the elbow extensors.

The first aim of this report was to document for the first time the joint kinematics and EMG activation patterns of the feline forelimb during upslope locomotion. The second aim was to document the effects of denervation and reinnervation of the long head of the triceps brachii (TLo) on joint kinematics and EMG of the shoulder and elbow during overground level and upslope walking in the cat; specifically, to document effects during two time points: (1) no to minimal activity in the TLo muscle (short-term effects of muscle nerve transection and repair) and (2) after motor function of this muscle has recovered but the stretch reflex has not (long-term effects of reinnervation). This is the first systematic report in which the denervation and reinnervation of the TLo, a biarticular antigravity muscle, on forelimb gait kinematics and EMG activation patterns have been assessed. This study was the first part of a larger project which investigated the effects of reinnervation of feline triceps brachii (TLo) and biceps brachii (Bi) muscles on joint kinematics and EMG during other mechanically challenging tasks, to be reported in subsequent papers, including downslope locomotion and visually guided reaching. Preliminary results on joint kinematics and EMG activity have been presented in abstract form [Livingston et al., 2002, 2004; Livingston and Nichols, 2005].

\section{Methods}

Animal Care and Training

All surgical and experimental procedures were consistent with the US Public Health Service Policy on Humane Care and Use of 
Fig. 1. Anatomical and schematic representation of the feline forelimb. a The orientation of the line of pull for the muscles of the elbow joint in the cat. b Illustration of the forelimb endpoints of the segments (scapula, humerus, forearm, carpals and digits) over which the reflective markers were placed are indicated by circles: the vertebral spine of the scapula, greater tuberosity of the humerus, ulnar styloid process $(2.5 \mathrm{~cm}$ proximal along the crest of the ulna), the 5th metacarpophalangeal joint (MCP) and the most distal part of the 5th toe. Joint angles were defined as included angles between the adjacent segments of the shoulder (glenohumeral), elbow, wrist, MCP and interphalangeal (toe) joints.

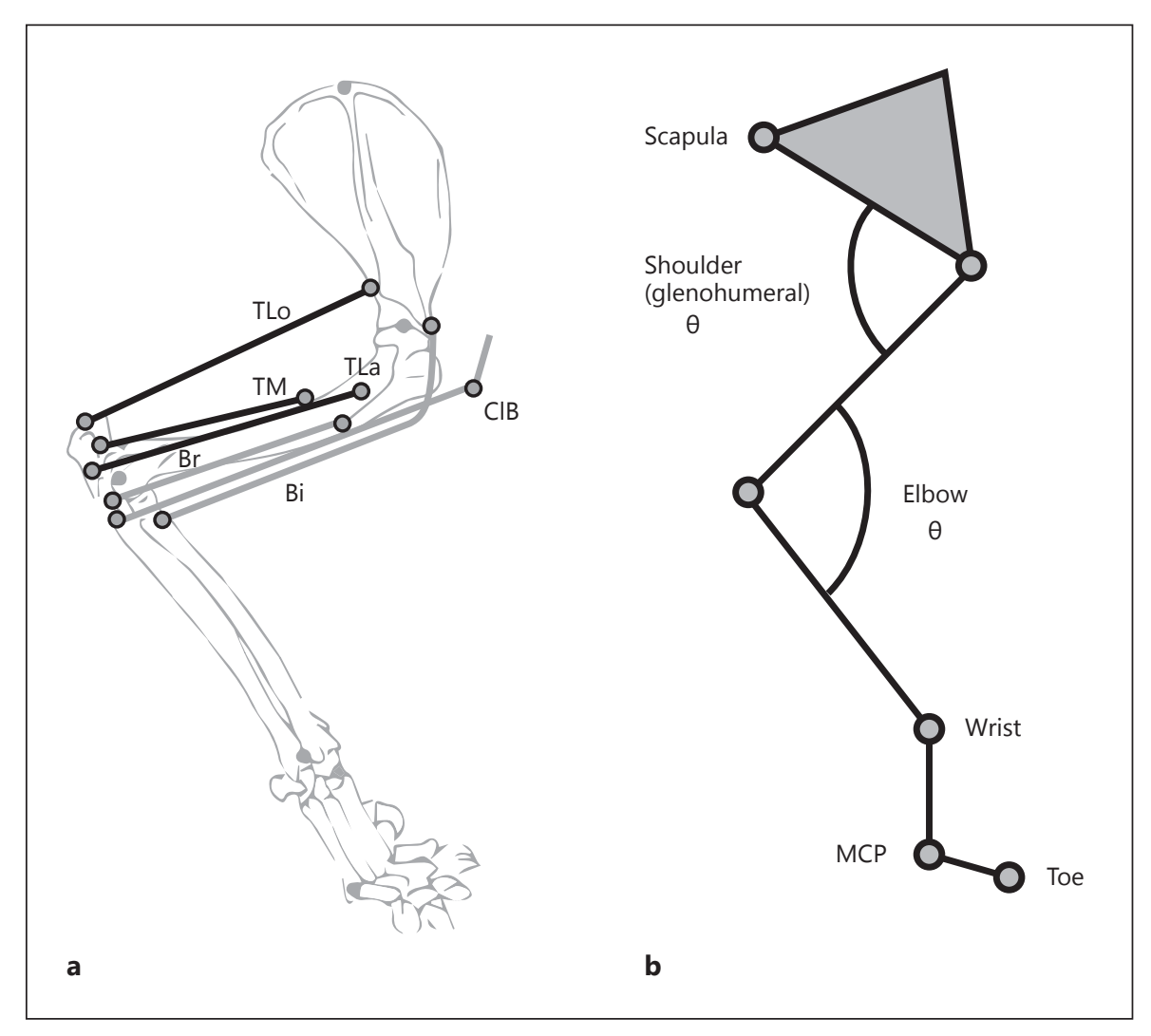

Laboratory Animals and according to the Guidelines for Research Involving Animals and were approved by the Institutional Animal Care and Use Committee of Emory University. All cats were housed in one large room of adequate space with access to food and water ad libitum. Six laboratory cats [Felis domesticus: 6 males (4.7-7.1 kg, average: $5.5 \mathrm{~kg}$ )] were trained for 3 months to walk on a walkway $(2.7 \times 0.33 \mathrm{~m})$. The walkway was inclined to one of three different grades: $0 \%$ (level), $25 \%$ (14 $4^{\circ}$ slope) and 50\% (26.6 $6^{\circ}$ slope). The surface of the walkway was covered with a non-slip polyester liner. During training sessions, food and affection were used to encourage walking. Thirty trials were recorded at each grade before surgery. There was no further training following the reinnervation surgery.

\section{Surgical Reinnervation}

All 6 cats were used for the surgical reinnervation procedure ( $\mathrm{n}=3$, TLo reinnervation; $\mathrm{n}=3$, Bi reinnervation). Animals were initially given atropine $(0.05 \mathrm{mg} / \mathrm{kg})$, ketamine $(10-30 \mathrm{mg} / \mathrm{kg})$ and valium $(1 \mathrm{mg} / \mathrm{kg})$ preoperatively, and anesthesia was maintained with isoflurane. Under sterile surgical conditions, an incision was made in the right axilla of each cat to expose the brachial plexus. Three cats (SL5t, NO3t and SP1t) had the radial nerve branch to the TLo muscle cut and immediately reattached, and 3 cats (WL6b, SM4b and JU2b) had the musculocutaneous nerve to the Bi muscle cut and reattached. Each nerve bundle was identified using electrical stimulation via a bipolar hook electrode. Special care was taken to minimize disruption of blood supply to the muscles and associated connective tissue. The proximal and distal nerve stumps were aligned and sutured together with two ties of nonabsorbable 22- $\mu \mathrm{m}$ (10-0) black monofilament nylon. The wound was closed, and the animal was allowed to recover with administration of analgesics $(0.0075 \mathrm{mg} / \mathrm{kg}$ Buprenex) and prophylactic antibiotics if needed.

Following surgery, the cats were place in individual cages and closely monitored while they recovered. Once they were able to eat, stand and use the litter box, they were returned to the colony to walk, run, jump, climb and interact with the other cats. Data collection was initiated about 2-4 weeks after they had recuperated. The cats were allowed 13-36 months of recovery from the date of surgery.

\section{Surgical EMG Implants}

Sterile surgical procedures were used for implanting EMG electrodes. During the surgery, pairs of Teflon-coated, multistranded, 38-gauge, stainless steel wires (AS633; Cooner Wire Co.) were implanted in selected forelimb muscles. A small section $(\sim 2-3 \mathrm{~mm})$ of insulation was scratched off each wire. The wires were pulled subcutaneously to a multipin connecter which was mounted and secured with small screws and dental acrylic to the skull. Four cats (SL5t, NO3t, JU2b and WL6b) had the electrode wires implanted prior to a nerve cut and reattachment, and 2 cats (SP1t and SM4b) were implanted 1 year after the nerve cut and reattachment. Cat SP1t had an anomaly in the radial nerve innervation of the TLo, and therefore these reinnervation data are not presented.

The following muscles were implanted: medial head (accessory portion) of the triceps (TM, elbow extensor), lateral head of the triceps (TLa, elbow extensor), TLo (elbow extensor and shoulder flexor; proximal or distal portion), cleidobrachialis (ClB, elbow 
flexor and shoulder extensor), brachialis (Br, elbow flexor) and the Bi (elbow flexor and shoulder extensor; fig. 1).

After surgical recovery in an individual cage, the cats were returned to a social colony in approximately 10 days. The animals were able to move freely within the colony for the duration of the survival period. Data collection was initiated about 2 weeks after the animals had recuperated.

\section{Assessment of Reflexes after Surgical Reinnervation}

After collection of all the kinematic and EMG data, the effects of TLo and Bi reinnervation on the integrity of the autogenic and heterogenic reflex pathways of the reinnervated muscles were assessed using the methods described by Nichols [1987, 1989, 1999]. Each cat was deeply anesthetized with isoflurane, and core temperature was maintained at $\sim 37^{\circ} \mathrm{C}$ with a heating pad. A tracheotomy was performed and the trachea cannulated for continued administration of the anesthetic. Both carotid arteries were exposed and surgical thread placed around them for later ligation prior to decerebration. A cannula was inserted in the left cephalic vein for the administration of fluids. Both upper forelimbs were exposed and the following muscles and tendons of insertion (with bone chip if possible) were dissected free from surrounding fascia and connective tissue and attached to tendon clamps: TLo, Bi and $\mathrm{Br}$. This was done to compare the properties of reinnervated muscle in one limb to the properties of untreated muscle in the other limb. Special care was taken to avoid bruising the muscles and to maintain their blood supply.

Animals were placed in a stereotaxic apparatus. The scapula was fixed by placing a clamp on the metacromion process and medial vertebral border of the scapula. The humerus was fixed proximally with a bone screw and distally with a clamp on the medial and lateral epicondyles. Each muscle tendon and clamp was connected to custom myographs consisting of two semiconductor strain gauges cemented to a U-shaped aluminum beam in series with four linear motors. Forces were measured using myographs mounted on linear slides through a universal joint to maintain alignment with the muscles. When possible, the muscles of both limbs were set at equal passive tension to equate the passive contributions within the same animal. Specifically, the reinnervated TLo (or $\mathrm{Bi}$ ) was set at the same background passive tension as the contralateral untreated TLo (or Bi), which usually positioned the muscles at similar lengths. A premammillary decerebration was performed by transecting the brainstem at an angle parallel to the bony tentorium rostral to the superior colliculus while preserving the mammillary bodies and subthalamic nucleus. Evacuation of all neural tissue rostral to the transection was performed. Saline-soaked Gelfoam strips and cotton balls were placed in the cranium to control bleeding. After decerebration, anesthetic was titrated down and then discontinued. All preliminary surgery was performed on a heating pad; after decerebration, the core temperature was monitored via rectal probe and maintained at $37^{\circ} \mathrm{C}$. Electrodes were placed on the left and right tibial nerves, and left and right superficial radial nerves to activate the forelimb musculature in a physiological manner through flexion withdraw or crossed extension reflex. Stimulation parameters were $50 \mathrm{~Hz}, 0.2$-ms pulse width square waves at 1.5-2.0 times the threshold (determined as the minimum current necessary to produce a visual contraction). Reflexes were evoked by ramphold-release (ramp duration $=50 \mathrm{~ms}$, amplitude $=2 \mathrm{~mm}$, hold period $=250 \mathrm{~ms}$ ) length perturbations. These parameters were chosen to activate large, myelinated afferent fibers. The force responses of the reinnervated muscles were compared with their untreated counterparts in the contralateral limb. At the end of each experiment, the animal was euthanized with an overdose of pentobarbital sodium (Nembutal, $150 \mathrm{mg} / \mathrm{kg}$ ) injected intravenously and a pneumothorax was performed.

\section{Data Analysis}

Kinematics

Each cat was tested in 3 series of experiments, i.e. (1) before reinnervation surgery, (2) 2 weeks (P2wks) and 1 month after surgery (P1mo; short term), and (3) >12 months after surgery (P12+mos; long term), and in three locomotion conditions, i.e. level, 25 and $50 \%$ upslope grades. Both forelimbs were shaved under sedation and retroreflective, spherical markers were placed over the vertebral spine of the scapula, the greater tuberosity of the humerus, the ulnar styloid process and approximately $2.5 \mathrm{~cm}$ proximal but along the ulna, the 5th metacarpophalangeal joint and the toe. Two-dimensional digital images of the markers were acquired with two $125-\mathrm{Hz}$ cameras oriented toward the ramp but greater than $60^{\circ}$ apart.

The markers were digitized using Peak ${ }^{\circledR}$ Motus software version 8.1. The position of the elbow joint marker was calculated by vector analysis. The known distance from the ulnar styloid process to the lateral epicondyle of the humerus was multiplied by the vector defined by the two ulnar markers in each cat. The data were smoothed with Fast Fourier transform using the optimal method with prescribed limit of 0.05 within the Peak Motus software. The three-dimensional coordinates were used to calculate joint angles for the shoulder and the elbow. The decrease in the included angles represents flexion and the increase in the included angles represents extension. One trial consisted of a complete step which was selected from the middle of a series of steps to avoid changes in acceleration. Paw-off (PO) and paw-contact (PC) were identified visually from the digitized images. Step cycle phases for the shoulder and elbow were identified according to Philippson [1905]. The swing phase ( $\mathrm{PO}$ to $\mathrm{PC}$ ) was subdivided into flexion phase (flexion of the elbow) and E1 phase (first extension of the elbow). The stance phase (PC to PO) was subdivided into E2 phase (yield of the elbow) and E3 phase (second extension of the elbow).

All joint kinematic data were time normalized. Plots of the joint angle as a function of time and as a function of joint angle were created to calculate differences in shoulder and elbow temporal and angular kinematic variables for each step cycle.

\section{EMG Data}

EMG signals were amplified with a gain of 1,000 and synchronized with the video via a voltage trigger. A custom computer program written in LabVIEW version 7.1 digitally converted the EMG signal at a sampling rate of $4 \mathrm{kHz}$ and then it was stored on a PC. The EMG files were then clipped in synchrony with the digital video $(125 \mathrm{~Hz})$ for a complete step cycle and converted to MATLAB files. The data were then analyzed using custom MATLAB software. The signals were bandpass filtered between 20 and 500 $\mathrm{Hz}$ with a 4th-order Butterworth filter. The files were then rectified and low-pass filtered at $15 \mathrm{~Hz}$. The burst onset and offset times for each muscle were determined by applying a amplitude threshold criterion (3 SD) for $50 \mathrm{~ms}$. Each muscle's burst duration was determined by subtracting the onset time from the offset time. In some cases, there were multiple bursts within a step cycle. The av- 
erage activity within each burst was calculated by dividing the sum of each sample within the burst (after processing) by the number of samples. The peak activity within each burst was determined by calculating the largest sample within each burst (after processing).

\section{Mechanographic Analysis}

The contribution of feedback from muscle receptors was detected using a mechanographic technique [Nichols, 1987]. The linear motors used in these experiments were Parker 404LXR motors with an encoder resolution of $0.1 \mu \mathrm{m}$, maximum acceleration of $5 \mathrm{~g}$ and maximum load capacity of $177 \mathrm{~N}$. Each linear motor was mounted on an aluminum frame and could be adjusted in horizontal, vertical and diagonal directions to achieve proper alignment with each muscle. The motors were controlled using a 6000 series Gemini servo drive, dSPACE board and Simulink program. The data were acquired digitally through the dSPACE board at a sampling rate of $1,000 \mathrm{~Hz}$. The change in length, velocity and hold time was specified using the data acquisition software built in Simulink with a graphical interface in ControlDesk. The typical paradigm was a $2-\mathrm{mm}$ stretch at a velocity of $40 \mathrm{~m} / \mathrm{s}, 100-\mathrm{ms}$ hold period and 2-mm release. The eccentric length change in the hindlimb that an intact animal experiences during the stance phase of walking is approximately $4 \mathrm{~mm}$ [Goslow et al., 1973a, b]. This conservative $2-\mathrm{mm}$ stretch was chosen to preserve the tendon and to increase the longevity of the preparation through repeated stretches.

The muscles were stretched in a two-state configuration. Length perturbations were specified using customized software, and actual length changes were recorded through an optical encoder. First, the recipient muscle (rTLo in the triceps reinnervation and the $\mathrm{rBi}$ in the biceps reinnervation) was administered a ramp and hold stretch alone. This was followed by a simultaneous stretch with the donor muscle ( $\mathrm{rBi}$ in the triceps reinnervation and the $\mathrm{rBr}$ in the biceps reinnervation). This stretching paradigm was done with the muscles in passive (before the removal of anesthesia) and active state (activated with flexion withdraw and crossed extension reflex). The tibial or superficial radial nerves were stimulated at twice the threshold, and stretches were imposed until the force decayed to prestimulation levels. Typically, 8-25 stretches were recorded per contraction. The two forelimbs underwent the same protocol in succession in order to compare responses obtained at the same initial force, while the reflex excitability of the animal was similar. A minimum of 5 min of rest was imposed between consecutive reflex activation.

A two-point calibration of the strain gauges was completed by calculating the voltage outputs with no load and with a 1-kg load. Linear interpolation between the two points was completed in MATLAB version 7.01 to calculate fits for each of the four myographs.

Custom-made software in MATLAB version 7.01 was used to analyze the acquired data. The background force of the individual muscles was calculated as an average of the force $10 \mathrm{~ms}$ prior to the beginning of the stretch, during the isometric hold period. A baseline was then fit to the $10 \mathrm{~ms}$ prior to stretch and the $10 \mathrm{~ms}$ following the return. The baseline was subtracted from the data to determine the force response. These force responses were then plotted as a function of background force, whereby each data point represents the response at $100 \mathrm{~ms}$ for an individual stretch. Quadratic equations and $95 \%$ confidence intervals are fitted to the two sets of data comparing the reinnervated and untreated muscles.

Effects of Reinnervation of Feline TLo during Upslope Walking
Table 1. Step cycle, stance and swing duration (in ms) at 0,25 and $50 \%$ grade

\begin{tabular}{|c|c|c|c|}
\hline & $0 \%$ & $25 \%$ & $50 \%$ \\
\hline \multicolumn{4}{|l|}{ Control } \\
\hline Cycle period & $611 \pm 83$ & $572 \pm 94$ & $580 \pm 97$ \\
\hline Stance period & $396 \pm 77$ & $356 \pm 88$ & $359 \pm 94$ \\
\hline Swing period & $215 \pm 19$ & $216 \pm 24$ & $221 \pm 25$ \\
\hline \multicolumn{4}{|l|}{ P2wks } \\
\hline Cycle period & $667 \pm 84$ & $670 \pm 97$ & $692 \pm 90$ \\
\hline Stance period & $437 \pm 80$ & $438 \pm 82$ & $463 \pm 101$ \\
\hline Swing period & $230 \pm 27$ & $230 \pm 25$ & $229 \pm 22$ \\
\hline \multicolumn{4}{|l|}{ Plmo } \\
\hline Cycle period & $638 \pm 96$ & $608 \pm 97$ & $677 \pm 148$ \\
\hline Stance period & $426 \pm 89$ & $400 \pm 90$ & $433 \pm 104$ \\
\hline Swing period & $212 \pm 21$ & $208 \pm 15$ & $244 \pm 13$ \\
\hline \multicolumn{4}{|l|}{$P 12+m o s$} \\
\hline Cycle period & $582 \pm 58$ & $600 \pm 70$ & $590 \pm 125$ \\
\hline Stance period & $378 \pm 51$ & $405 \pm 79$ & $390 \pm 90$ \\
\hline Swing period & $204 \pm 15$ & $195 \pm 13$ & $200 \pm 14$ \\
\hline
\end{tabular}

Values are means \pm SD for control ( $n=6$ cats), P2wks $(n=3$ cats), $P 1 \mathrm{mo}(\mathrm{n}=3$ cats $)$ and $\mathrm{P} 12+\operatorname{mos}(\mathrm{n}=3$ cats $)$ time points. $\mathrm{n}=$ 10 -30 steps/grade.

\section{Statistics}

To compare various kinematic and EMG parameters for level and upslope walking both before and after surgery, repeated-measure analysis of variance in conjunction with a general linear model (Statistical Package for the Social Sciences, SPSS ${ }^{\circledR}$ version 14.0 for Windows) was used. Tukey's post hoc test was used to test differences between cell means. Statements indicating a quantitative difference between data sets are based on a significance level of $\mathrm{p} \leq 0.05$.

\section{Results}

\section{Comparison of Level and Upslope Locomotion \\ Kinematics}

Means and standard deviations of the stance, swing and step cycle duration are reported for all 6 cats during the control trials (table 1) and for 2 cats (NO3t and SL5t) during the denervation-reinnervation trials. Step cycle periods were all within the range of $400-900 \mathrm{~ms}$, which is consistent with moderate walking speed [Smith et al., 1993]. There was no significant difference in average walking speeds with grade. However, although not statistically significant, the greatest variability in speed was across cats; therefore, in order to reduce the possibility 


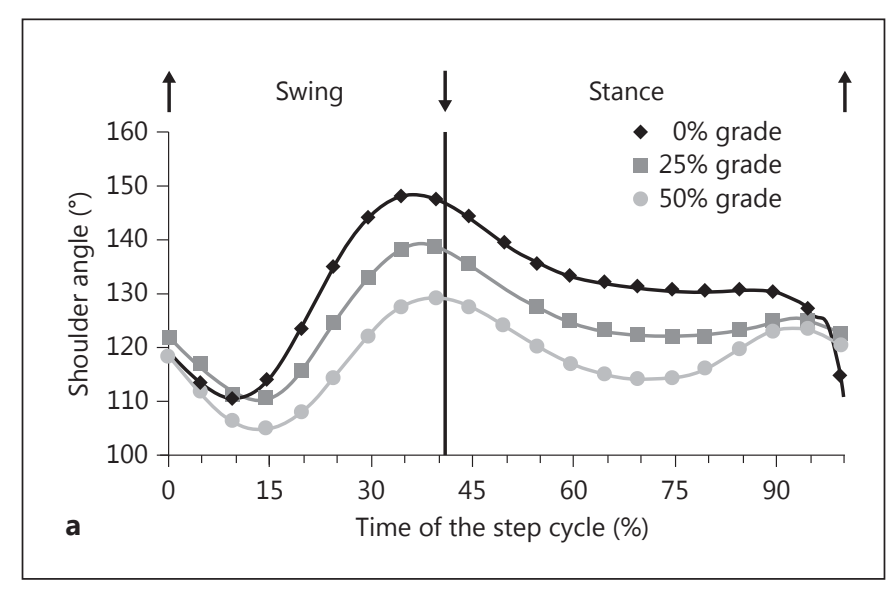

Fig. 2. a, b Joint angle-time plots for the shoulder (a) and elbow joint (b) during level ( $0 \%$ grade) and upslope ( 25 and $50 \%$ grade) walking for cat SP1t. Values are the means of 30 time-normalized steps. The graph begins and ends with PO $(\uparrow)$ and between them is PC $(\downarrow)$ of the step cycle. c Shoulder-elbow angle-angle plots for level ( $0 \%$ grade) and upslope ( 25 and $50 \%$ grades) walking for cat SL5t. Values are the time-normalized averages from 30 steps. For each cyclograph, the step cycle starts and ends with $\mathrm{PO}$ and reads in the clockwise direction. Stance phase is delimited by PC to PO, and marked by dashed lines, and swing is marked with solid lines. Data points are plotted for each frame (8-ms intervals).

that speed-related differences would be confounded with slope-related differences, each cat served as its own control for the presentation of the kinematic and EMG data.

Exemplar joint angle-time plots for the shoulder and elbow are illustrated in figure $2 \mathrm{a}, \mathrm{b}$. In table 2 , the mean shoulder and elbow joint positions during each step cycle transition are listed for the 2 cats (SL5t and NO3t) that underwent successful TLo reinnervation. At all three grades of walking, the pattern of angular displacement for the shoulder and elbow joints was consistent for all 6 control cats (data not shown).

\section{Swing Phase}

At the onset of swing, both joints were in flexion to lift the paw, and at the end of swing, both joints extended (E1) to place the paw for contact with the ground. Irrespective of the grade, the reversal from flexion to E1 occurred first at the shoulder joint and then at the elbow
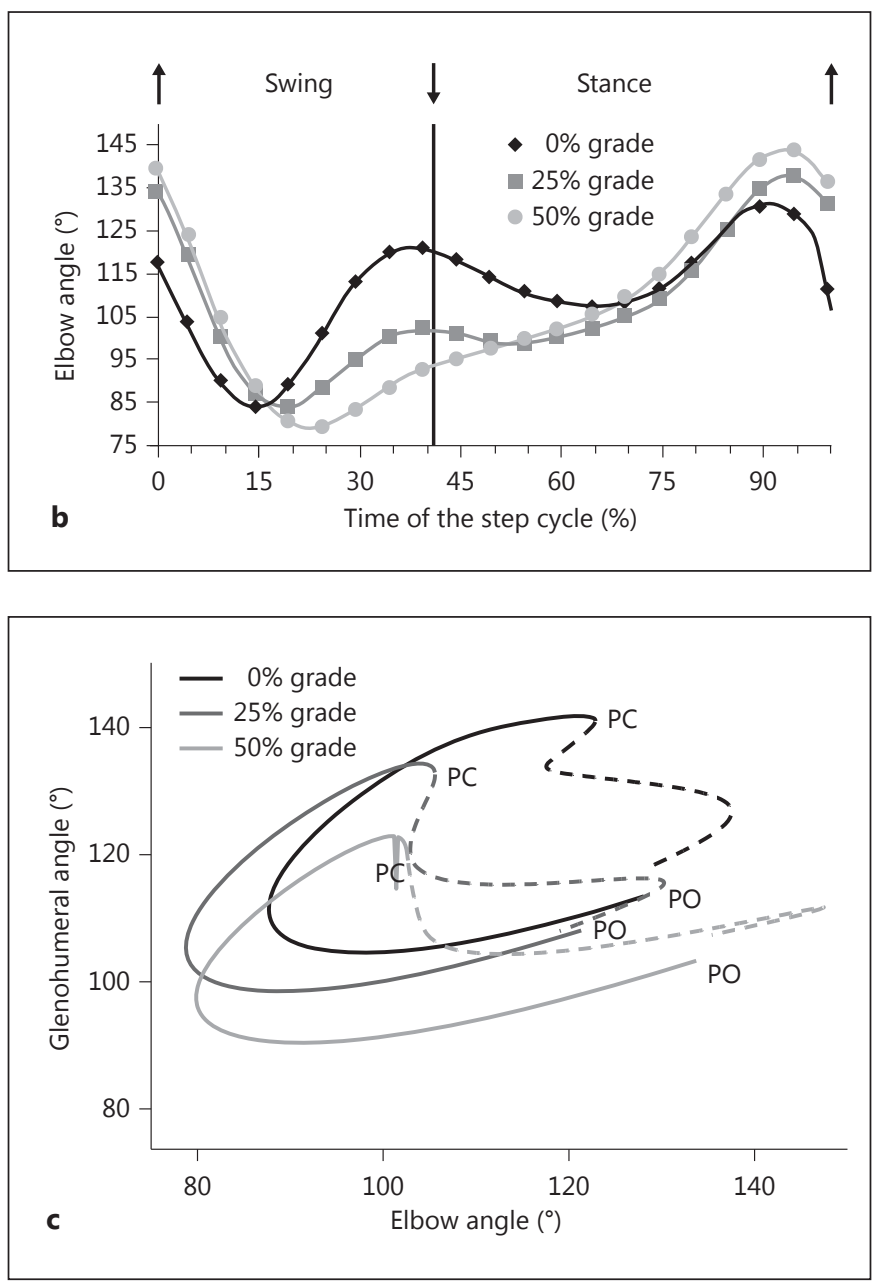

(fig. 2a, b). At the $50 \%$ grade of upslope walking, the elbow joint was significantly more extended at PO than during level walking. At the termination of swing and the beginning of stance, PC, the elbow joint was significantly more flexed at the $50 \%$ grade than during level walking. During the transition from flexion to E1, in the middle of swing, there was no significant change in the position of shoulder or elbow joints with the increased grade of slope walking.

\section{Stance Phase}

At the beginning of stance during level walking, both the shoulder and the elbow joints flexed (E2 phase; fig. 2a, b). However, at the $50 \%$ grade of upslope walking, there was a slight flexion at the shoulder joint and no flexion at the elbow. Irrespective of the grade, the reversal from E2 to E3 occurred first at the elbow joint and then at the shoulder (fig. 2a, b). At the 50\% grade of upslope walking, 
Table 2. Angular positions of the forelimb shoulder and elbow joints (in ${ }^{\circ}$ ) at step cycle transitions for the TLo denervation/reinnervation

\begin{tabular}{|c|c|c|c|c|c|c|c|c|c|}
\hline & Time & & & & & & & & \\
\hline & control & & & P2wks & & & P1mo & & \\
\hline & $0 \%$ & $25 \%$ & $50 \%$ & $0 \%$ & $25 \%$ & $50 \%$ & $0 \%$ & $25 \%$ & $50 \%$ \\
\hline Shoulde & & & & & & & & & \\
\hline $\mathrm{PO}$ & $114 \pm 8$ & $109 \pm 6$ & $104 \pm 6^{\mathrm{a}}$ & $130 \pm 3^{b}$ & $109 \pm 4$ & $110 \pm 4^{c}$ & $118 \pm 4$ & $106 \pm 8$ & $105 \pm 4$ \\
\hline F-E1 & $105 \pm 16$ & $98 \pm 4$ & $91 \pm 3$ & $125 \pm 2^{b}$ & $97 \pm 5$ & $103 \pm 3^{c}$ & $113 \pm 3$ & $99 \pm 8$ & $101 \pm 4$ \\
\hline $\mathrm{PC}$ & $142 \pm 10$ & $134 \pm 4$ & $120 \pm 7^{\mathrm{a}}$ & $162 \pm 3^{b}$ & $137 \pm 7$ & $130 \pm 7^{c}$ & $150 \pm 3$ & $127 \pm 11$ & $121 \pm 2$ \\
\hline E2-E3 & $127 \pm 18$ & $113 \pm 6$ & $104 \pm 7^{\mathrm{a}}$ & $136 \pm 10$ & $112 \pm 6$ & $110 \pm 3^{c}$ & $121 \pm 6$ & $113 \pm 11$ & $112 \pm 5$ \\
\hline Peak E & $129 \pm 19$ & $116 \pm 7$ & $114 \pm 7$ & $136 \pm 11$ & $113 \pm 7$ & $110 \pm 3^{c}$ & $121 \pm 7$ & $114 \pm 12$ & $115 \pm 6$ \\
\hline Elbow & & & & & & & & & \\
\hline $\mathrm{PO}$ & $128 \pm 8$ & $121 \pm 7$ & $134 \pm 10^{\mathrm{a}}$ & $120 \pm 9$ & $134 \pm 9$ & $113 \pm 4^{\mathrm{c}}$ & $124 \pm 10$ & $109 \pm 7$ & $117 \pm 10$ \\
\hline F-E1 & $86 \pm 14$ & $76 \pm 6$ & $78 \pm 5$ & $92 \pm 5$ & $91 \pm 7$ & $76 \pm 3$ & $93 \pm 7$ & $72 \pm 7$ & $74 \pm 10$ \\
\hline $\mathrm{PC}$ & $123 \pm 11$ & $105 \pm 8$ & $102 \pm 9^{a}$ & $122 \pm 4$ & $117 \pm 8$ & $89 \pm 5^{c}$ & $130 \pm 7$ & $94 \pm 11$ & $86 \pm 8^{\mathrm{d}}$ \\
\hline E2-E3 & $115 \pm 12$ & $100 \pm 9$ & $100 \pm 9$ & $104 \pm 4^{b}$ & $106 \pm 6$ & $86 \pm 3^{c}$ & $122 \pm 10$ & $90 \pm 8$ & $86 \pm 8^{\mathrm{d}}$ \\
\hline Peak E & $138 \pm 8$ & $131 \pm 7$ & $149 \pm 7^{a}$ & $131 \pm 8$ & $139 \pm 10$ & $122 \pm 5^{c}$ & $142 \pm 6$ & $126 \pm 9$ & $132 \pm 7^{\mathrm{d}}$ \\
\hline
\end{tabular}

Values are means \pm SD from 10-30 steps per grade for 2 cats (SP1t and SL5t). F-E1 = Swing flexion-extension reversal; Peak $\mathrm{E}=$ stance phase peak extension. ${ }^{\mathrm{a}} \mathrm{p} \leq 0.05,{ }^{\mathrm{b}} \mathrm{p} \leq 0.05$ vs. $0 \%$ control; ${ }^{\mathrm{c}} \mathrm{p} \leq 0.05,{ }^{\mathrm{d}} \mathrm{p} \leq 0.05$ vs. $50 \%$ control.

the elbow position at peak extension was significantly greater than level walking (table 2). As evident by these findings, the elbow joint appears to contribute more to the propulsion of the animal in graded walking.

\section{Interjoint Coordination}

Changes in interjoint coordination between the shoulder and elbow joints were assessed by angle-angle plots (cyclographs; fig. 2c). The shift in the cyclograph to the lower left corner of the graph indicates a greater degree of both shoulder and elbow flexion during the $50 \%$ grade of upslope walking. The increase in angular excursion by the elbow joint as compared to the shoulder joint at the 50\% grade during flexion and E3 is evident as compared to level walking.

Contour changes in the shoulder-elbow cyclograph during the stance phase were related to the grade of upslope walking. During level walking, the stance phase (dashed line) was characterized by flexion of both joints (E2 phase or yield), followed by a period of extension predominantly at the elbow (E3). As slope increased to 25 and then $50 \%$, the coordinated yield during E2 of both joints was replaced by a decoupling of joint movement such that flexion of the shoulder was accompanied by extension of the elbow. For all three slopes, extension during E3 occurred predominantly at the elbow joint, indi- cating a major contribution of the elbow joint to propulsion and shoulder joint to stabilization.

\section{Comparison of Motor Patterns of Select Shoulder and}

Elbow Muscles during Upslope Walking

Typical EMG traces illustrate the activity of the elbow extensors (fig. 3a) and the elbow flexors (fig. 3b) for both level and upslope walking.

\section{Stance-Related Muscle Activity}

The two monoarticular muscles (TM and TLa), with extensor function at the elbow, had predominantly stance-related activity. The activity began prior to PC during E1 (to extend the elbow) and continued for most of stance (fig. 3a). There was no significant change in the duration of these two elbow extensor bursts with steepness of graded walking (fig. 4a). However, there was a significant increase in the average burst amplitude of these two extensors as the cats progressed from level to 50\% grade of upslope walking (fig. $4 \mathrm{~b}$ ). The TM average burst amplitude increased from $107 \mathrm{mV}$ during level walking to $187 \mathrm{mV}$ during $50 \%$ grade of upslope walking, and the TLa increased from 96 to $234 \mathrm{mV}$.

The biarticular muscle (TLo), with extensor function at the elbow joint and flexor function at the shoulder joint during a concentric contraction, was active predominate- 


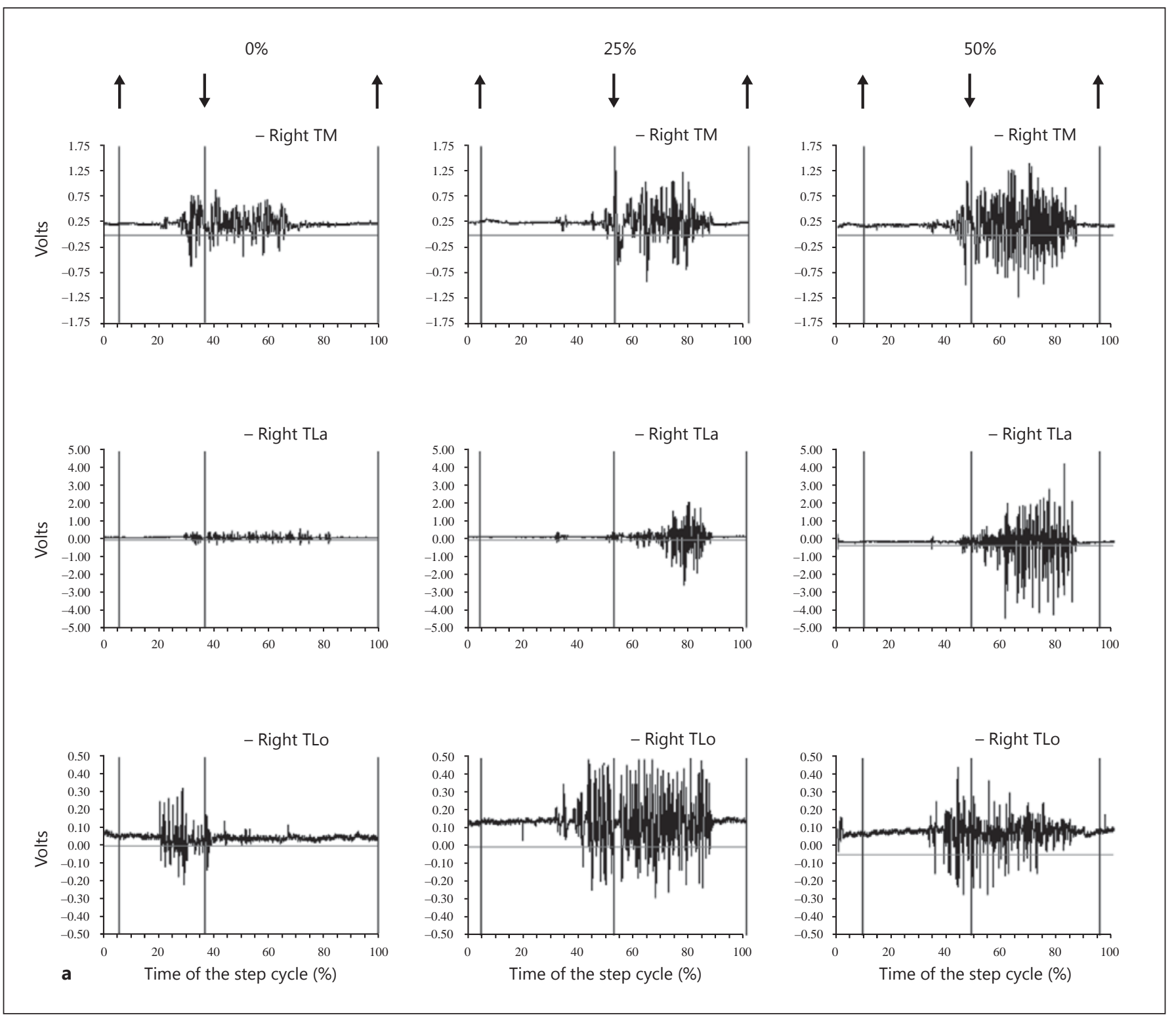

Fig. 3. Raw EMG records from the elbow extensor (a) and flexor (b) muscle groups from a representative step cycle for level and upslope walking for cat SL5t. $\uparrow=\mathrm{PO} ;=$ PC.

(For figure $3 b$ see next page.)

ly during stance of upslope locomotion (fig. 3a) consistent with a role for propulsion. The TLo showed substantial activity during late swing (E1) in all walking conditions. Both the TLo's average burst duration and the average burst amplitude increased significantly during $50 \%$ grade of upslope walking as compared to level walking (fig. 4a, b). The TLo average burst duration increased from $166 \pm 38 \mathrm{~ms}$ during level walking to $314 \pm 82 \mathrm{~ms}$ during the $50 \%$ grade.

\section{Swing-Related Muscle Activity}

The one monoarticular muscle (Br), with flexor function at the elbow joint, had predominately swing-related activity. The activity began prior to PO (as the paw was being unweighted) and continued until the termination of the flexion phase of swing followed by a very small burst just prior to PC (fig. 3b). There was a significant increase in the Br first burst duration and average amplitude (fig. 4c, d) with the grade of upslope walking. The 


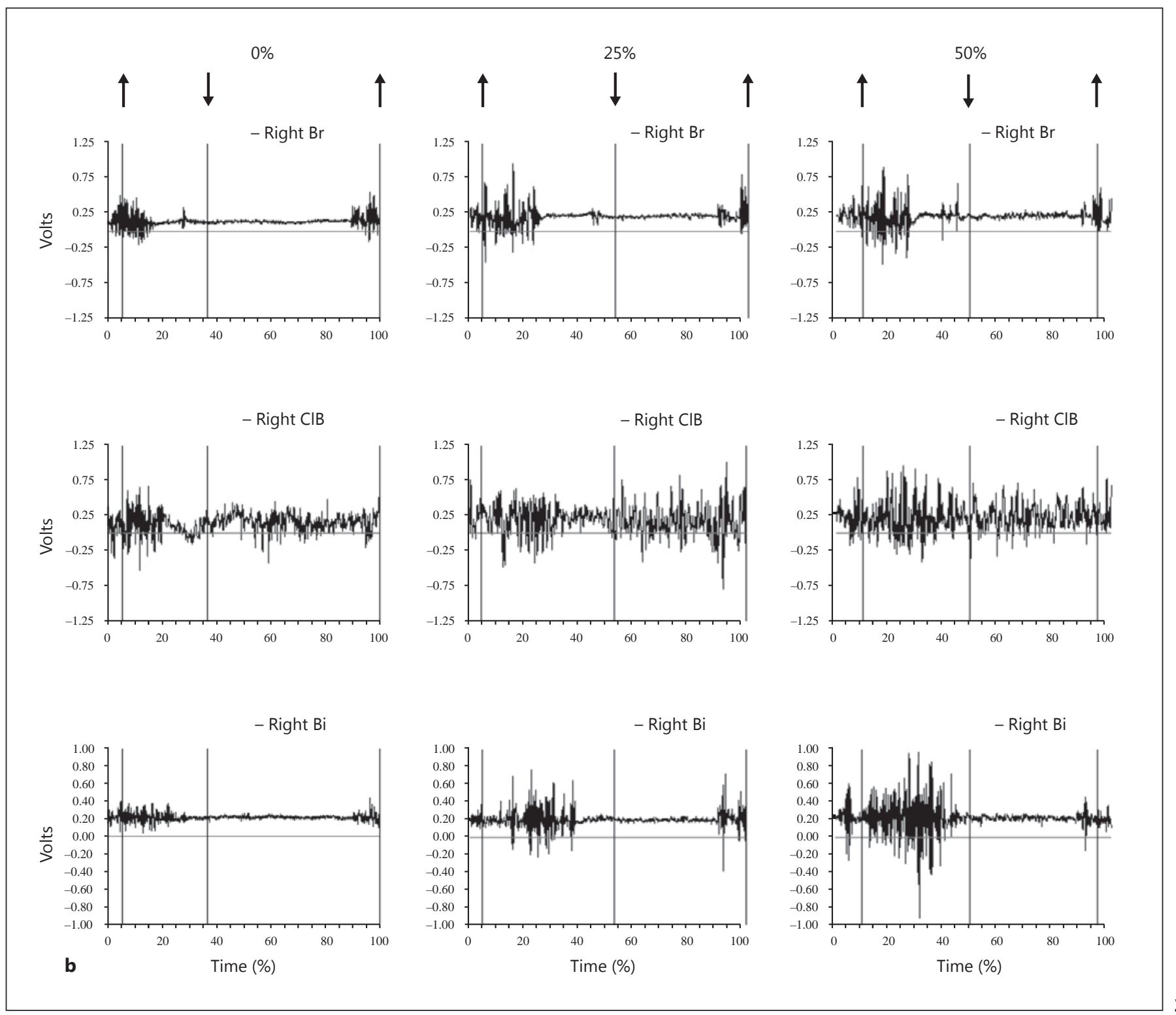

average swing burst duration increased from 105 to 160 $\mathrm{ms}$ as the range of elbow flexion increased from 35 to $58^{\circ}$ (fig. 2a).

The two biarticular muscles ( $\mathrm{ClB}$ and $\mathrm{Bi})$, with flexor function at the elbow joint and extensor function at the shoulder joint during a concentric contraction, were also predominately active during the swing phase of walking and began prior to PO (fig. $3 \mathrm{~b}$ ). There was a significant increase in the $\mathrm{ClB}$ and the Bi's first burst duration and average amplitude (fig. 4c, d) with the grade of upslope walking. The $\mathrm{ClB}$ and $\mathrm{Bi}$ increased their average burst duration from 161 and $216 \mathrm{~ms}$, respectively, at level walking

Effects of Reinnervation of Feline TLo during Upslope Walking to 282 and $312 \mathrm{~ms}$ at $50 \%$ grade of upslope walking, respectively. There was a small but significant change in the average burst amplitude of $\mathrm{ClB}$ and $\mathrm{Bi}$ with $50 \%$ grade of upslope walking.

\section{Effects of TLo Muscle Nerve Transection and Repair} on Joint Kinematics and Interjoint Coordination

For all three walking conditions, the shoulder and elbow joint kinematics of the reinnervated forelimb changed at the 2-week time period following TLo reinnervation (table 2). However, to simplify the data set, only the level (0\%) grade and the $50 \%$ grade of slope walking 

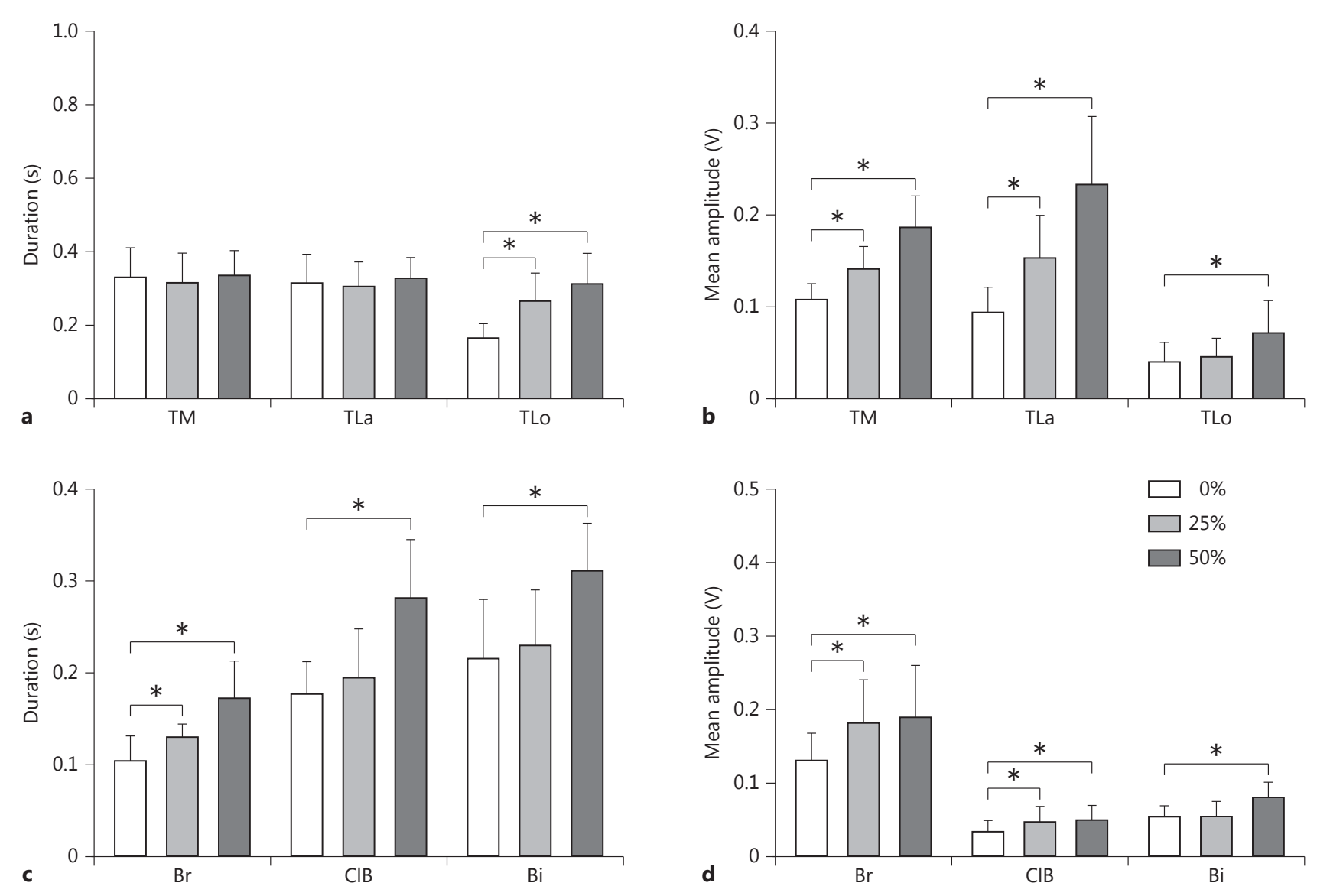

Fig. 4. Comparison of control EMG burst duration and average amplitude of the extensor muscles (cat SL5t) and the elbow flexors (cat WL6b) for level and upslope walking. Values are the means \pm SD of 30 steps. a, c Burst duration. $\mathbf{b}, \mathbf{d}$ Mean burst amplitude. ${ }^{*} \mathrm{p} \leq 0.05$.

will be discussed. With the paralysis of TLo during the P2wks time frame, one would expect the kinematic and interjoint coordination changes would occur during the stance phase and at the termination of the swing phase of locomotion as this is when the muscle was active (fig. 3 ). Coordination between the shoulder and elbow joints was assessed using angle-angle plots (fig. 5, 6). A positive slope represents simultaneous flexion or extension of each joint, while a negative slope represents movement of the two joints in the opposite direction (i.e. shoulder flexion and elbow extension).

\section{Level Walking Kinematics}

In the control condition, the shoulder-elbow plot during early stance (PC-E2) was characterized by a positive slope which illustrated that both the shoulder and elbow joints were flexing together (fig. $5 \mathrm{a}, \mathrm{d}$ ). Two weeks to 1 month after the transection and repair of the TLo muscle nerve, the shoulder-elbow plot during early stance (PCE2) was characterized by a more horizontal line with lower slope (fig. 5e). This change in slope, during early stance, demonstrates a significant increase in elbow flexion (table 2: E2-E3) with little change in shoulder flexion. Shoulder-elbow coordination during stance gradually returned to a positive slope and was indistinguishable from that of the control condition at P12+mos (fig. 5c, f).

\section{Upslope Walking Kinematics}

Short-term effects of the transection and repair of the TLo muscle nerve resulted in a significant change in the angular position of the shoulder and elbow joints throughout the step cycle at P2wks (table 2). Specifically, the position of the elbow joint during PC, E2-E3 (peak elbow yield) and peak E (peak elbow extension) was significant- 


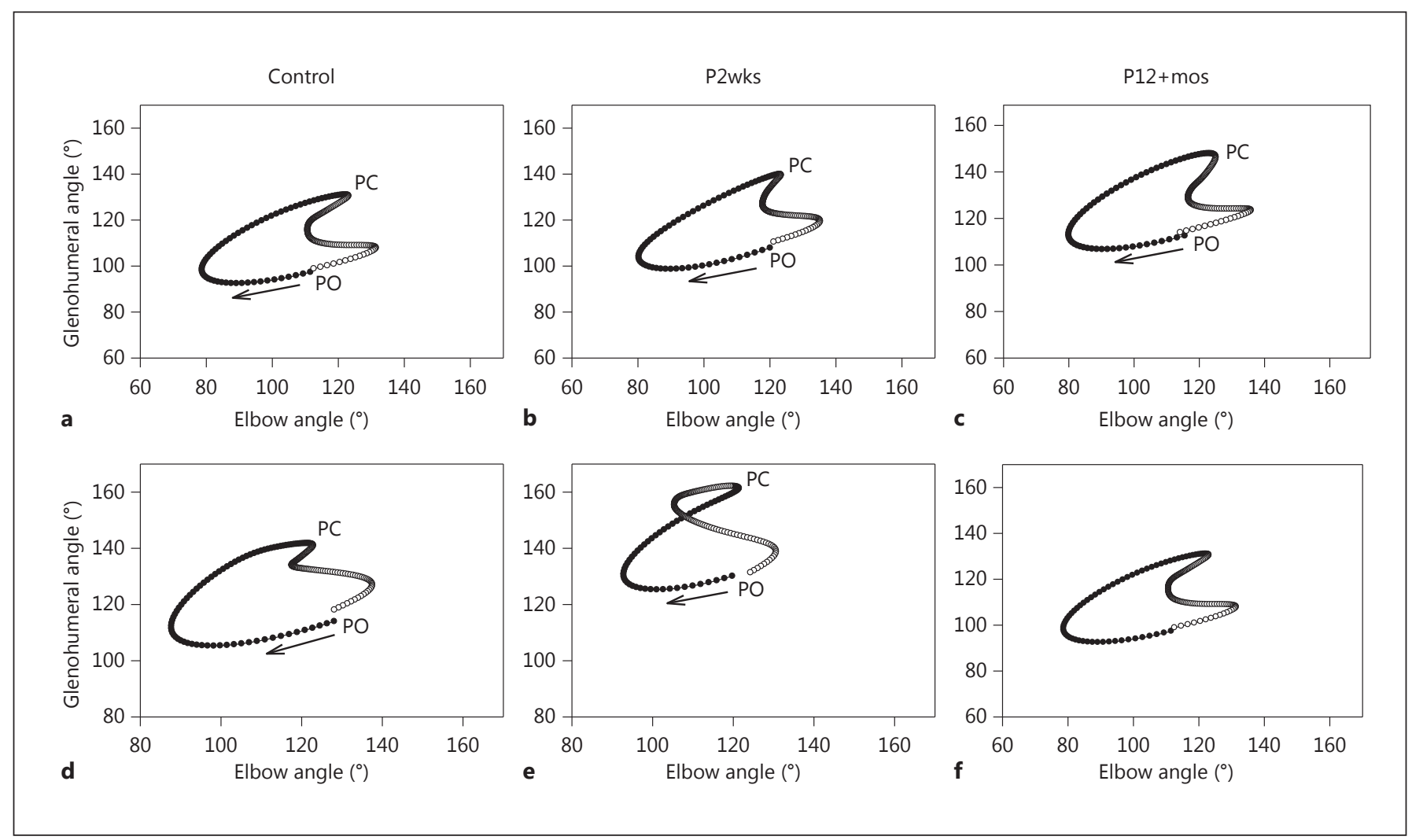

Fig. 5. Shoulder-elbow angle-angle plots for level (0\% grade) walking following transection and repair of the radial nerve to the TLo. Values are the time-normalized averages from 10-30 steps. a Control: $0 \%$ grade for cat NO3t $(n=30)$. b P2wks: $0 \%$ grade for cat
NO3t $(n=10)$. $\mathbf{c ~ P 1 2 + m o s : ~} \% \%$ grade for cat NO3t $(n=10)$. $\mathbf{d}$ Control: $0 \%$ grade for cat SL5t $(\mathrm{n}=30)$. e P2 wks: $0 \%$ grade for cat SL5t $(n=10)$. f P12+mos: $0 \%$ grade for cat SL5t $(n=10)$. ly more flexed than the control condition, and the shoulder joint was more extended during PC and E2-E3 transition.

In the control condition, during the $50 \%$ grade of upslope walking, the slope of the shoulder-elbow plot from PC to E2 was essentially a vertical line indicating that the shoulder was flexing with little change in the elbow position (fig. 6a, d). Furthermore, from E2 to E3, the slope was essentially a horizontal line indicating that the elbow was extending exclusively (fig. 6a, d). At the time interval from P2wks to P1mo, the shoulder-elbow plot during the stance phase of upslope walking consisted of a negative slope relationship (fig. 6b, e). The negative slope region of the shoulder-elbow plot indicated that the shoulder was flexing and the elbow was extending. Interjoint coordination gradually returned to the control condition for the $50 \%$ grade of upslope walking at $\mathrm{P} 12+$ mos (fig. 6c, f).

Effects of Reinnervation of Feline TLo during Upslope Walking

\section{Effects of TLo Muscle Nerve Transection and Repair} on EMG Activation Patterns

The change in the EMG activity of the elbow extensors for 0 and $50 \%$ grade of walking is illustrated in figure 7 . During the paralysis of the biarticular TLo (fig. 7e), the monoarticular TM and TLa significantly increased their burst duration and average burst amplitude (fig. $7 \mathrm{a}-\mathrm{d}$ ). In the short-term recovery, following the return of some of the EMG activity in the TLo (fig. 7e), the burst duration remained elevated as compared to control conditions. However, the average burst amplitude of the TM and TLa, monoarticular elbow extensors, returned toward the control values (fig. $7 \mathrm{~b}, \mathrm{~d}$ ).

\section{Effects of TLo Reinnervation on Reflex Integrity}

Crossed extension reflex provided a slowly decaying background force to obtain the force dependence of the responses. A loss of the reflex action in the reinnervated muscle was noted if two of the following responses on the 


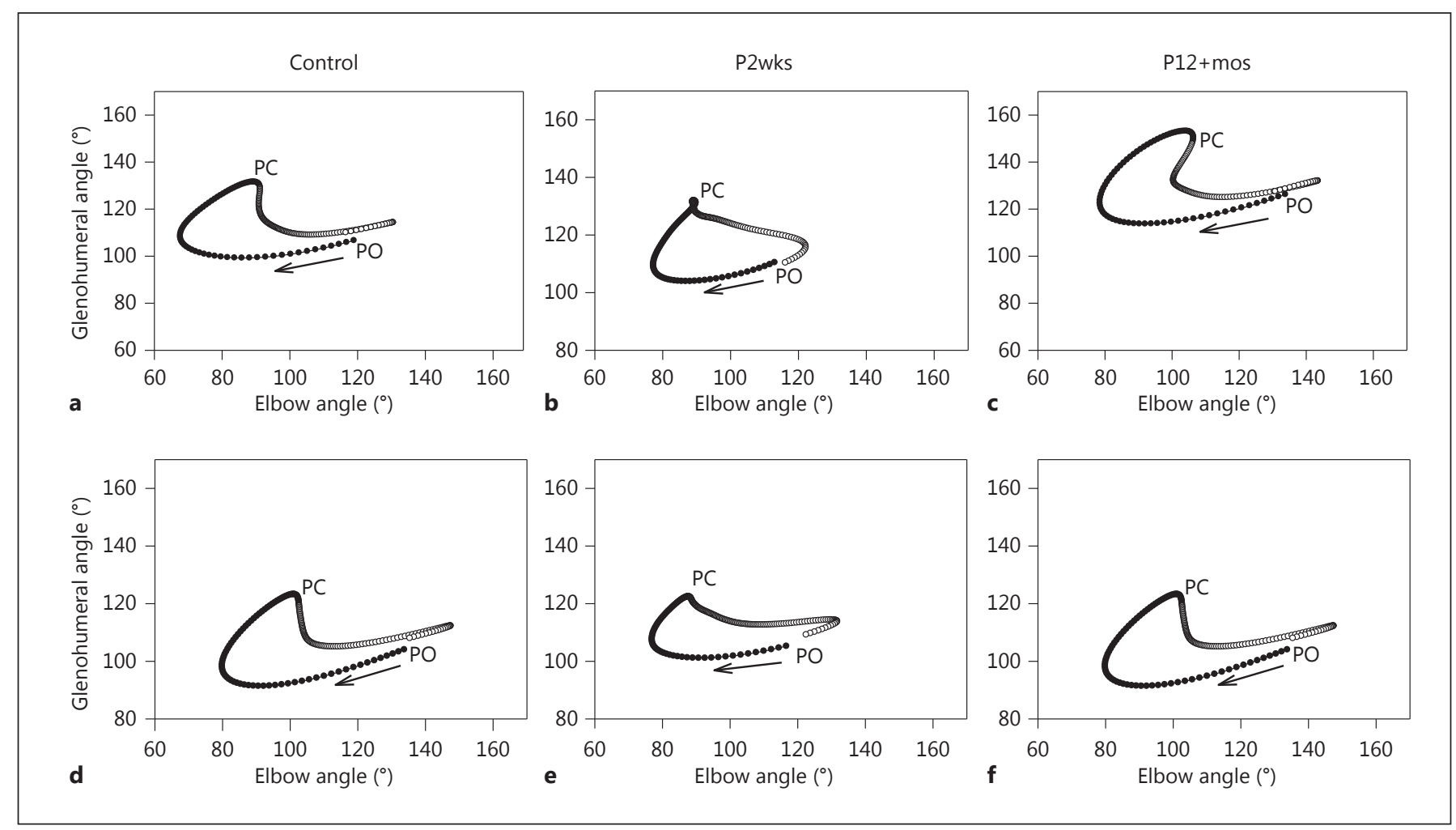

Fig. 6. Shoulder-elbow angle-angle plots for upslope (50\% grade) walking following transection and repair of the radial nerve to the TLo. Values are the time-normalized averages from 10-30 steps. a Control: $50 \%$ grade for cat NO3t $(\mathrm{n}=30)$. b P2wks: $50 \%$ grade for cat NO3t $(n=10)$. c P12+mos: $50 \%$ grade for cat NO3t $(n=10)$. d Control: $50 \%$ grade for cat SL5t $(n=30)$. e P2wks: $50 \%$ grade for cat SL5t $(n=10)$. f P12+mos: $50 \%$ grade for cat SL5t $(n=10)$. reinnervated side were observed: (1) a reduction in the magnitude of the force responses; (2) an increase in yielding and adaptation of these responses, and (3) an increase in force dependence [Nichols and Houk, 1976; Huyghues-Despointes et al., 2003a, b]. This is illustrated in figure 8 . In figure $8 \mathrm{a}$, reflex responses of both the right TLo (reinnervated) and the left TLo (control) muscles at matching initial forces are shown superimposed. There is a clear reduction in the magnitude of the force response and an increased adaptation following the termination of the ramp stretch in a ramp and hold stretch. Also, the slope of the force-time plot is reduced at the termination of the ramp, indicating a reduction in stiffness beyond the short range of the muscle. The plots in figure $8 \mathrm{~b}$ are force responses obtained during the hold phase of the ramp and hold stretch, and are plotted as a function of the background force of the decaying cross-extension reflexes. Again, the magnitude of the responses on the reinnervated side are reduced severalfold over the range for which data were taken on both sides. This occurred in 2 of the 3 animals which had the TLo reinnervated. The 3rd animal (SP1t) was noted to have an anatomical anomaly in that the TLo was innervated distally by another branch of the radial nerve.

\section{Discussion}

The goals of this project were twofold. First, to understand the adjustments in joint kinematics, interjoint coordination, and changes in motor patterns of the forelimb shoulder and elbow muscles during slope walking. Our second goal was to understand the effects of denervation and reinnervation of the biarticular TLo on the multifunctional forelimb. This study documents, for the first time, the adjustments in forelimb kinematics, coordination and EMG activity of the elbow musculature during level and upslope walking, and following the transection and repair of the TLo muscle nerve. 

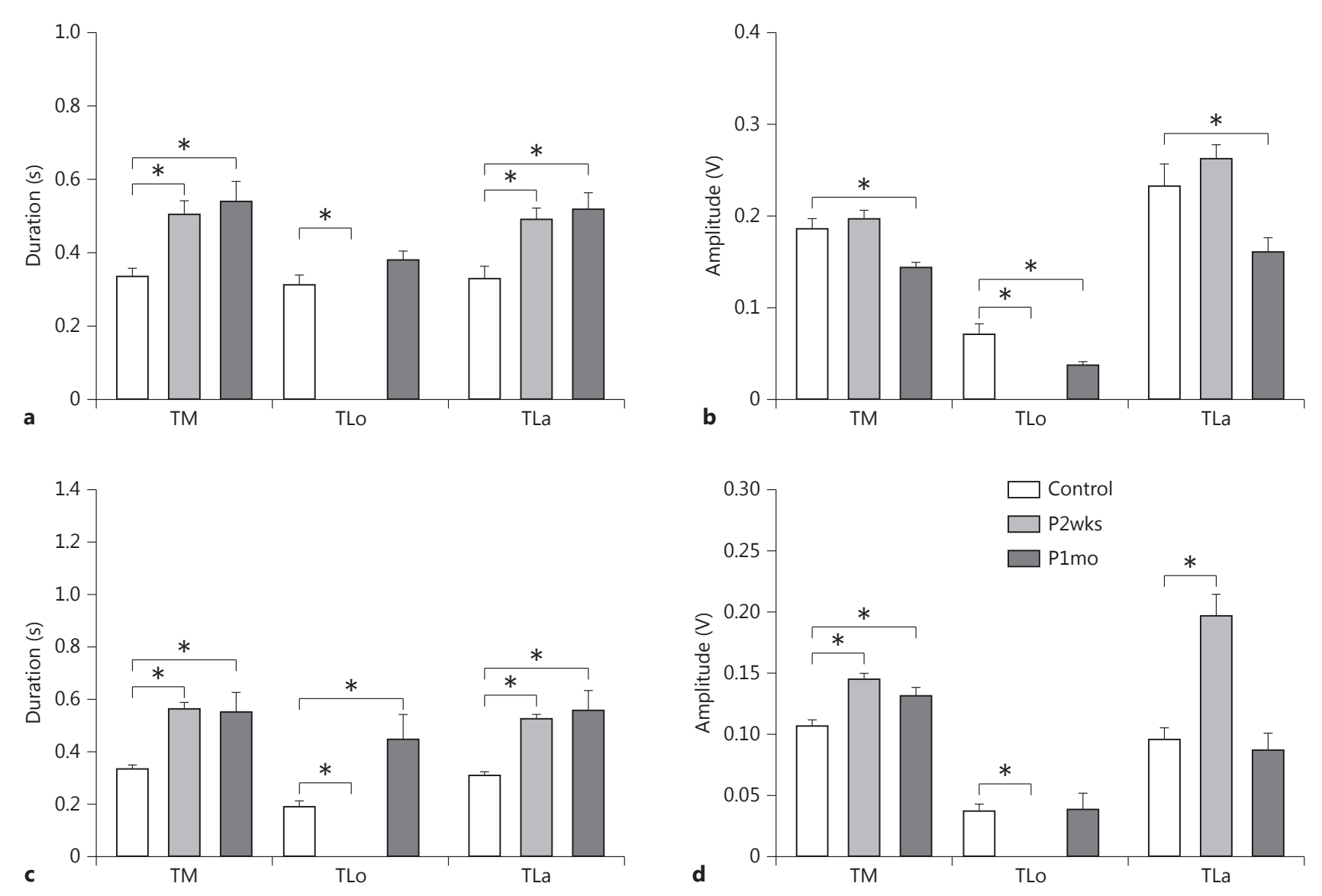

Fig. 7. Comparison of EMG adaptations in the elbow extensor muscle group for $50 \%$ grade upslope walking. Values are means \pm SE for $n=30$ control steps, and $n=10$ for P2wks and P1mo, respectively. Burst duration (a, c) and average burst amplitude (b, d)

for cat SL5t (a, b) and cat NO3t (c, d) at 50\% grade. e Sample of the rectified EMG data for cat SL5t during 50\% grade upslope walking.

(For figure 7 e see next page.)

Four major findings resulted from this study. First, we described how the kinematics and muscular activity patterns of the feline forelimb are modified during upslope walking to move the body mass forward and upward during the stance phase of locomotion. The coordination strategy involved the decomposition of the shoulder and elbow joints during early stance as the slope grade increases. Also, there was an increase in the average burst amplitude of the elbow extensors during upslope walking that reflects the increased demand to move the body mass forward and upward. Second, despite the motor redundancy that exists, paralysis of the TLo, a biarticular muscle which spans both the shoulder and elbow joints, resulted in altered joint kinematics. Third, as the EMG activity begins to return in the treated muscles, the joint kinematics showed evidence of returning to the control condition. Finally, in the long term, as the TLo regained its efferent innervation and while the muscle was without length-dependent reflex action, the shoulder and elbow kinematics for level and upslope walking were restored to levels before injury.

\section{Upslope-Related Changes in Forelimb Joint}

\section{Kinematics and Motor Patterns}

During level walking, the shoulder and elbow joint angles of the forelimb recorded in this study underwent phases of flexion, extension and angular excursions during the step cycle similar to those reported by other authors [Miller and Van der Meché, 1975; English, 1978; Drew and Rossignol, 1987; Caliebe et al., 1991; Rossignol, 


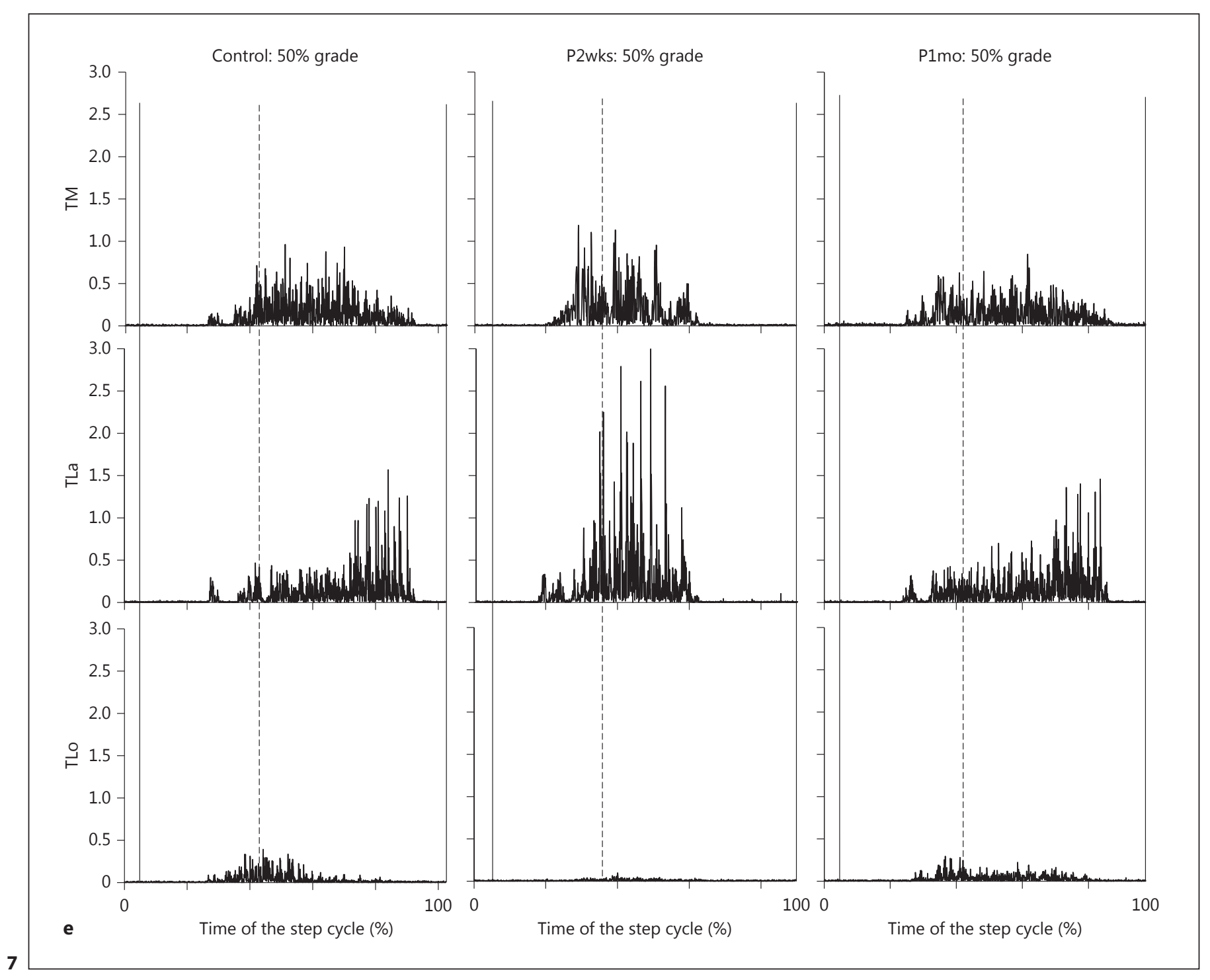

1996]. However, during quadrupedal upslope walking, there are different geometrical constraints and power requirements in order to accomplish this challenging task. The forelimb must be moved forward and placed on the incline such that the body mass can be moved forward, upward and over the forelimb during stance. During swing, the forelimb must be accelerated forward to place the paw on a surface that is inclined at different angles. Furthermore, we infer that the power requirements for upslope walking would be greater than level walking as the cat's mass is moved upward. During the entire stance phase of level walking, the forelimb vertical ground reaction force was positive and reached values around 18$22 \mathrm{~N}$ [Prilutsky et al., 2005], which were typical for mam- malian locomotion. Because these forces were higher in the forelimb, the values of the joint moment peaks were generally larger than in the hindlimb [Manter, 1938; Pandy et al., 1988] as the center of mass is closer to the forelimbs. During stance, the elbow joint exerts an extensor moment with a peak around mid-stance, then changes to flexion at the end of stance to prepare for swing. Among the joints of the forelimb, the elbow contributes the most to power production and thus forward propulsion [Prilutsky et al., 2005].

During the swing phase of upslope walking, there were some unique relationships between the shoulder and the elbow joint. First, at PO there was no change in the shoulder position with grade, but the elbow joint was in a posi- 


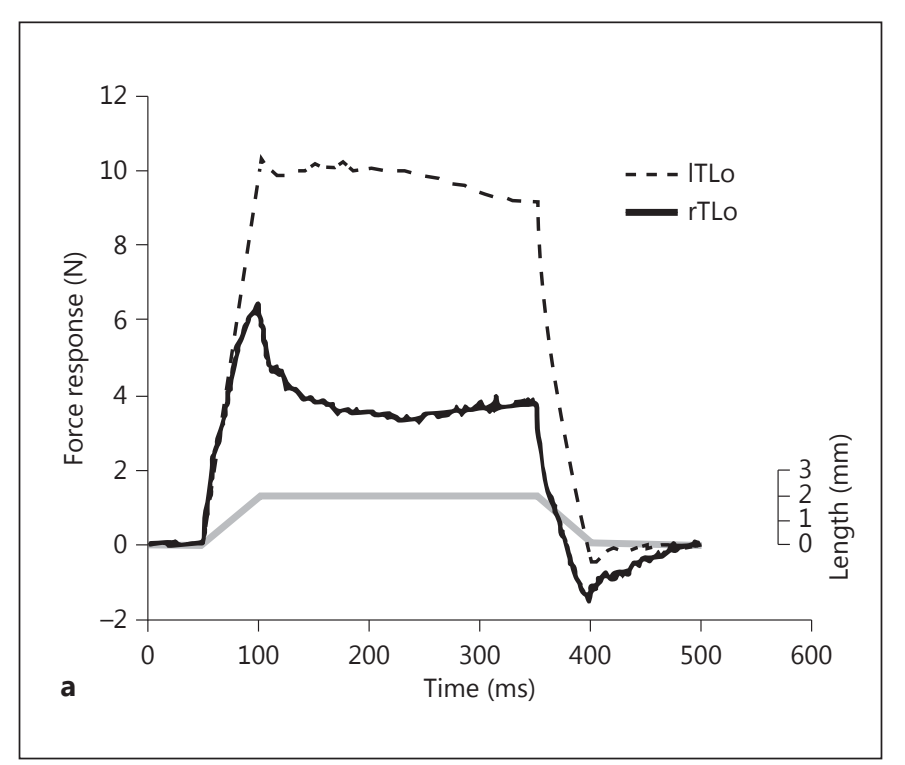

Fig. 8. Comparison of stretch-evoked responses in reinnervated and contralateral TLo muscles from cat SL5t, but similar results were found in the other cats. a Superimposed force responses from the reinnervated (black, bottom trace) and the contralateral (dashed, top trace) muscles (TLo) obtained at matching initial forces together with the imposed length changes (gray line). b The muscle responses obtained during the hold phase (absolute force

tion of greater extension. This would be consistent with the elbow contributing the most positive power generation and thus forward propulsion during stance [Prilutsky et al., 2005]. During flexion and E1, there was greater elbow flexion and less elbow extension, respectively, with grade. This is to be expected in order to accommodate the paw to the inclined surface. Furthermore, the transition from flexion to E1 always occurred first at the shoulder and then at the elbow for all three grades. This is an indication that during this acceleration of the forelimb the movement occurs first at the more proximal joint.

During the stance phase of upslope walking, there was a progressive decrease in yield during E2 at the elbow with the increase in grade of slope to a point of no yield during the $50 \%$ grade. Because the elbow is more flexed at PC, increasing the yield would lower the center of mass and require more energy expenditure for propulsion and might place the elbow extensors in a poor length-tension relationship. The E2-E3 transition always occurred first at the elbow and then at the shoulder, no matter what the grade. This is an indication that during this weight-bearing stage, the forelimb extension occurs first at the more distal joint.

Effects of Reinnervation of Feline TLo during Upslope Walking

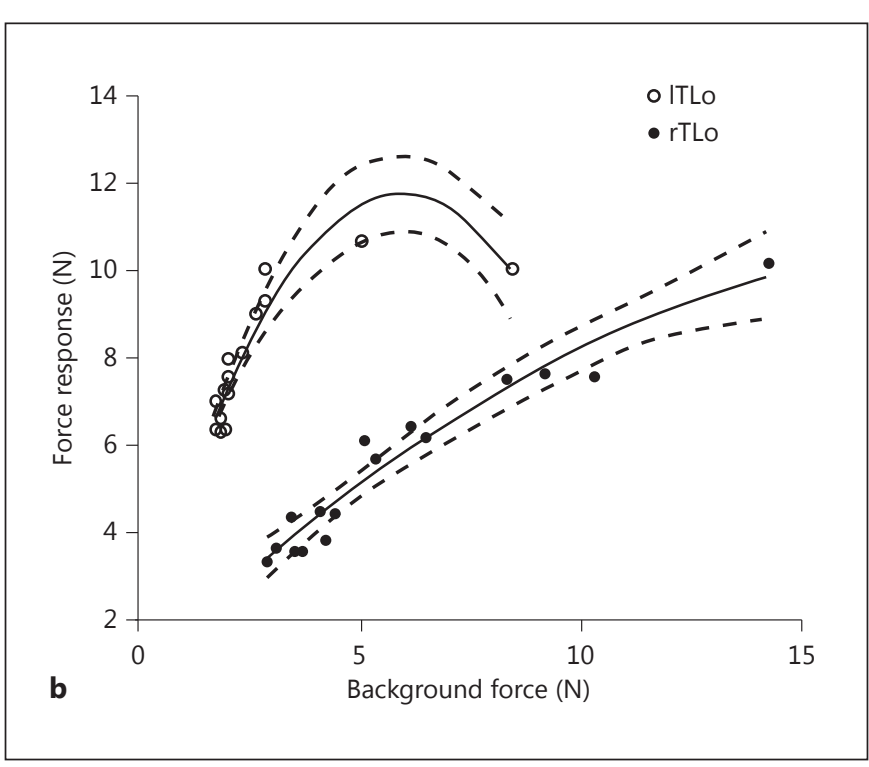

minus background at $\mathrm{t}=250 \mathrm{~ms}$ ) plotted as a function of background force during the decaying crossed extension reflex. The points were fitted with a second-order polynomial with the reinnervated TLo (black circles) and the contralateral TLo (open circles) and the dashed lines indicate the $95 \%$ confidence intervals. This figure clearly illustrates the loss of the stretch reflex action in the reinnervated TLo muscle.

There were two changes in the activity patterns for upslope walking that were expected. There was an increase in flexor activity during swing and an increase in extensor activity during stance. There are two major ways to increase the acceleration (power) of the forelimb and the force production of the antigravity muscles during upslope walking: one is by increasing the amplitude of EMG through recruitment and rate modulation and two is by increasing the duration of the activity. Both mechanisms were observed in our investigation of the elbow musculature during upslope walking.

\section{Adaptations to Walking during Paralysis (Short-Term Effect)}

A fundamental issue in the neuromuscular control of movement is the extent to which the nervous system is capable of choosing different muscle activity patterns to produce similar joint kinematics. However, our results were similar to what occurred in the hindlimb with the paralysis of the biarticular ankle extensors (medial/lateral gastrocnemius) [Pearson et al., 1999; Maas et al., 2007]. With the motor redundancy of the musculature about the shoulder and elbow, one would expect the ner- 
vous system to activate another shoulder-elbow muscle to compensate. However, if this occurred, then the compensation was incomplete as evident by the increased yield at the elbow during E2 and the altered shoulderelbow coordination. Studies in the hindlimb using botulinum toxin to effectively block neuromuscular transmission in the lateral gastrocnemius, plantaris and soleus resulted in a greater ankle yield during E2 of level walking and increased EMG in the medial gastrocnemius [Misiaszek and Pearson, 2002]. However, the recovery of ankle kinematics was much faster (approx. 11 days) and more complete than the 4 weeks (P1mo) in the forelimb. These results could be explained in two ways. First, botulinum toxin just blocks the motor transmission leaving the afferent feedback from the affected muscles intact and capable of contributing via heterogenic feedback to the intact ankle plantar flexors. It is estimated that approximately $20 \%$ of the total Ia monosynaptic input to the medial gastrocnemius can be assumed to be absent after denervation [Burke and Rymer, 1976]. Second, with a greater load being borne by the forelimb, the recovery of the net force generation from all elbow extensor may take longer. During the recovery, the average burst amplitude of the TLo synergist (TM and TL) returns to control level, while the burst duration remained longer than control. From a functional point of view, the increase in duration of activity could contribute to a reduction in the yield during early stance and could represent an increase in central drive, and the increase in burst amplitude would contribute to enhanced elbow extension during stance. This similar pattern occurred in the medial gastrocnemius of the hindlimb following partial denervation of the synergist in the triceps surae [Gritsenko et al., 2001]. This provides evidence that the neuromuscular system adapts at least partially in a functionally relevant way.

It appears from the control kinematics and EMG activation patterns that the motor control strategy during upslope locomotion was to move the center of mass of the cat up and over the somewhat fixed elbow joint, and if there was a large yield at the elbow, this would not be efficient. After transection and repair, the neuromuscular system did not compensate for the yield. The explanation for the inability of the remaining elbow extensors to compensate may lie in the difference in fiber-type profiles and contractile properties of the feline elbow extensors. The estimated percentage of slow-twitch, oxidative fibers in the TLa were $0-20 \%$, in the TM (accessory portion) 61$80 \%$ and in the TLo $21-40 \%$ [Collatos et al., 1977]. The contraction time of the TM was approximately $60 \mathrm{~ms}$ and considerably longer than the fast TLa at $30 \mathrm{~ms}$. There is also a difference in the frequency range over which fast and slow muscles increase tension. Maximum tension is obtained from slow muscles by increasing firing frequency by only 30 pulses per second [Collatos et al., 1977]. Thus, there is not a broad range of firing frequency that can increase the tension development in these remaining elbow extensors. During the recovery, the average burst amplitudes of the TM and TLa synergist return to control levels, while the burst duration remained longer than control. From a functional point of view, the increase in duration would contribute to a reduction in the yield during early stance and could represent an increase in central drive. Yet the compensation was incomplete.

In summary, the denervation of TLo soon after transection and repair resulted in substantially altered forelimb joint kinematics as well as interjoint coordination and muscle activity patterns for both walking conditions. These short-term effects can be explained by both mechanical and neural factors without complete preservation of the individual joints or shoulder-elbow joint coordination patterns. These results may suggest and support that joint angle combinations are coordinated and selected to stabilize whole limb kinematics against shortterm natural step-by-step deviations as well as pathological deviations created by injury as demonstrated in the hindlimb [Chang et al., 2009].

\section{Adaptations to Walking following Reinnervation \\ (Long-Term Recovery)}

One of the major findings of this study was the full recovery of forelimb shoulder and elbow kinematics during level and upslope walking despite the absence of length feedback from the only biarticular elbow extensor, the TLo.

Just as in the hindlimb, it is not likely that the forcegenerating capacity of the elbow extensor, TLo, was compromised as a result of the reinnervation. The mass of the TLo was not significantly different from the contralateral control, and muscle activity 3-4 months after reinnervation was very close to the control conditions [unreported data]. This was in agreement with previous studies using similar procedures in the hindlimb [Gordon and Stein, 1982a, b; Cope and Clark, 1993; Cope et al., 1994].

In contrast to the motor recovery, we found that reinnervation leads to a long-term effect on the disruption of sensory length feedback (fig. 8). A critical issue in the neuromuscular control of movement is the role and contribution of short-latency proprioceptive feedback from muscles. Stretch-evoked reflexes have been shown to con- 
tribute to the mechanical properties of muscles by compensating for nonlinear properties of muscle [Nichols and Houk, 1976; Huyghues-Despointes et al., 2003a, b] and therefore regulating antigravity support during standing [Sherrington, 1906; Nichols, 2002] and locomotion [Pearson et al., 1999; Stein et al., 2000]. However, the role of excitatory force feedback, which is predominately autogenic in the hindlimb [Ross and Nichols, 2009], could explain the short-term changes in kinematics that returned after the force production in the TLo returned.

After reinnervation of the biarticular shoulder flexor and elbow extensor (TLo), during level and upslope walking, there were no long-term changes in the shoulder and elbow joint kinematics. These results are in agreement with studies of level and upslope locomotion in the hindlimb [Abelew et al., 2000] and may be explained by the contractile conditions during level and upslope walking. In the hindlimb, muscle fibers of the medial gastrocnemius muscle (biarticular knee flexor and ankle extensor) shortened or remained at a constant length while the muscle tendon unit lengthened [Gregor et al., 2006; Maas et al., 2009] during E2 of upslope locomotion. Therefore, the role of length feedback might not be as critical during this type of mechanical and contractile condition. Although there is no quantification of the muscle load and fiber length changes in the forelimb muscles with either level or upslope walking in this study, it appears the longterm effects of reinnervation on kinematics and muscle activity were the same as in the hindlimb, suggesting the TLo muscle was undergoing a shortening contraction (concentric) during level and upslope walking. During such a contractile condition, concentric contraction, only a small contribution by length feedback is expected [Nichols and Houk, 1976a, b; Cordo and Rymer, 1982; Huyghues-Despointes et al., 2003a, b]. These data suggest that the local disruption of proprioceptive feedback has been compensated by other mechanisms, possibly by the use of other sensory feedback (i.e. cutaneous receptors in the paw, or length and force feedback receptors from the unaffected synergist) or by altered central drive.

\section{Conclusion}

We have described the manner in which feline forelimb kinematics and muscular activation patterns are modified during upslope walking, a mechanically challenging task, to move the body mass of the cat forward and upward during the stance phase of locomotion. Soon after nerve transection and surgical repair of the nerve to TLo, there was a failure to maintain normal joint kinematics and muscle activity during level or upslope locomotion despite the presence of other untreated synergistic muscles, yet it should be noted that the TLo was the only biarticular elbow extensor. However, as the biarticular TLo muscle is subsequently reinnervated and with the recovery of the motor function and the attenuation of the length feedback, kinematics and EMG activity of the elbow muscles during level and upslope walking begin to return to normal, suggesting that full recovery of the proprioceptive loss is compensated for by other sensory sources or altered central drive.

\section{Acknowledgments}

We would like to thank Arick Augang, Andrea Burgess, Brandon Buckner, Chris Chuong, Jinger Gottshall, Ginny LaMon, Melissa Miller, Gareth Nichols and Kyla Ross for their help in training and collecting data. We would also like to thank Boris Prilutsky and Robert Gregor for their help with making and implanting the EMG electrodes during the surgery, and Michael Boyles, graphic designer, for his assistance with the figures. This research was supported by NS 40405-03.

\section{References}

Effects of Reinnervation of Feline TLo during Upslope Walking

\footnotetext{
Abelew, T.A., M.D. Miller, T.C. Cope, T.R. Nichols (2000) Local loss of proprioception results in disruption of interjoint coordination during locomotion in the cat. J Neurophysiol 84: 2709-2714.

Alexander, R. (1980) Optimum walking techniques for quadrepeds and bipeds. J Zool 192: 97-117.

Alvarez, F.J., H.E. Titus-Mitchell, K.L. Bullinger, M. Kraszpulski, P. Nardelli, T.C. Cope (2011) Permanent central synaptic disconnection of proprioceptors after nerve injury and regeneration. I. Loss of VGLUT1/IA synapses on

motoneurons. J Neurophysiol 106: 24502470.

Bullinger, K.L., P. Nardelli, M.J. Pinter, F.J. Alvarez, T.C. Cope (2011) Permanent central synaptic disconnection of proprioceptors after nerve injury and regeneration. II. Loss of functional connectivity with motoneurons. J Neurophysiol 106: 2471-2485.

Burke, R.E., W.Z. Rymer (1976) Relative strength of synaptic input from short-latency pathways to motor units of defined type in cat medial gastrocnemius. J Neurophysiol 39: 447458 .
} 
Caliebe, F., J. Häubetaler, P. Hoffmann, M. Illert, J. Schirrmacher, E. Wiedemann (1991) Cat distal forelimb joints and locomotion: an Xray study. Eur J Neurosci 3: 18-31.

-Chang, Y.H., A.G. Auyang, J.P. Scholz, T.R. Nichols (2009) Whole limb kinematics are preferentially conserved over individual joint kinematics after peripheral nerve injury. J Exp Biol 212: 3511-3521.

Collatos, T.C., V.R. Edgerton, J.L. Smith, B.R. Botterman (1977) Contractile properties and fiber type compositions of flexors and extensors of elbow joint in cat: implications for motor control. J Neurophysiol 40: 1292-1300.

Cope, T.C., S.J. Bonasera, T.R. Nichols (1994) Reinnervated muscles fail to produce stretch reflexes. J Neurophysiol 71: 817-820.

Cope, T.C., B.D. Clark (1993) Motor-unit recruitment in self-reinnervated muscle. J Neurophysiol 70: 1787-1796.

Cope, T.C., C.B. Webb, B.R. Botterman (1991) Control of motor-unit tension by rate modulation during sustained contractions in reinnervated cat muscle. J Neurophysiol 65: 648-656.

-Cordo, P.J., W.Z. Rymer (1982) Contributions of motor-unit recruitment and rate modulation of compensation for muscle yielding. J Neurophysiol 47: 797-809.

Drew, T., S. Rossignol (1987) A kinematic and electromyographic study of cutaneous reflexes evoked from the forelimb of unrestrained walking cats. J Neurophysiol 57: 1160-1184.

English, A.W. (1978) An electromyographic analysis of forelimb muscles during overground stepping in the cat. J Exp Biol 76: 105-122.

Foehring, R.C., G.W. Sypert, J.B. Munson (1986) Properties of self-reinnervated motor units of medial gastrocnemius of cat. I. Long-term reinnervation. J Neurophysiol 55: 931-946.

-Gordon, T., R.B. Stein (1982a) Reorganization of motor-unit properties in reinnervated muscles of the cat. J Neurophysiol 48: 1175-1190.

Gordon, T., R.B. Stein (1982b) Time course and extent of recovery in reinnervated motor units of cat triceps surae muscles. J Physiol 323: 307-323.

-Goslow, G.E., Jr, R.M. Reinking, D.G. Stuart (1973a) The cat step cycle: hind limb joint angles and muscle lengths during unrestrained locomotion. J Morphol 141: 1-41.

-Goslow, G.E., Jr, R.M. Reinking, D.G. Stuart (1973b) Physiological extent, range and rate of muscle stretch for soleus, medial gastrocnemius and tibialis anterior in the cat. Pflügers Arch 341: 77-86.

Gregor, R.J., B.I. Prilutsky, T.R. Nichols, W. Smith (2003) EMG output in reinnervated medial gastrocnemius muscle during locomotion in the cat. New Orleans, Society for Neuroscience (online program No 493.8).

- Gregor, R., D. Smith, B. Prilustsky (2006) Mechanics of slope walking in the cat: quantification of muscle load, length change and ankle extensor EMG patterns. J Neurophysiol 95: 1397-1409.

Gregor, R.J., J.L. Smith, D.W. Smith, A. Oliver, B.I. Prilutsky (2001) Hindlimb kinetics and neural control during slope walking in the cat: unexpected findings. J Appl Biomech 17: 277-286.

-Gritsenko, V., V. Muschahwar, A. Prochazka (2001) Adaptive changes in locomotor control after partial denervation of triceps surae muscles in the cat. J Physiol 533: 299-311.

-Herzog, W., T. Leonard, A. Guimaraes (1993) Forces in gastrocnemius, soleus, and plantaris tendons of the freely moving cat. J Biomech 26: 945-953.

Hodgson, J.A. (1983) The relationship between soleus and gastrocnemius muscle activity in conscious cats: a model for motor unit recruitment. J Physiol 337: 553-562.

Huyghues-Despointes, C.M.J.I., T.C. Cope, T.R. Nichols (2003a) Intrinsic properties and reflex compensation in reinnervated triceps surae muscles of the cat: effect of activation level. J Neurophysiol 90: 1537-1546.

Huyghues-Despointes, C.M.J.I., T.C. Cope, T.R. Nichols (2003b) Intrinsic properties and reflex compensation in reinnervated triceps surae muscles of the cat: effect of movement history. J Neurophysiol 90: 1547-1555.

Kaya, M., A. Jinha, T.R. Leonard, W. Herzog (2005) Multi-functionality of the cat medical gastrocnemius during locomotion. J Biomech 38: 1291-1301.

Kaya, M., T. Leonard, W. Herzog (2003) Coordination of medial gastrocnemius and soleus forces during cat locomotion. J Exp Biol 206: 3645-3655.

Lehmann, J.F., S.M. Condon, B.J. de Lateur, J.C. Smith (1985) Ankle-foot orthoses: effect on gait abnormalities in tibial nerve paralysis. Arch Phys Med Rehabil 66: 212-218.

Livingston, B.P., T. Abelew, T.R. Nichols (2004) Kinematic analysis of visually guided reaching in denervated and reinnervated biceps and triceps of the feline forelimb. San Diego, Society for Neuroscience.

Livingston, B.P., Y.H. Chang, T. Abelew, T.R. Nichols (2002) Kinematic analysis of the feline forelimb during level and slope walking and visually guided reaching. Orlando, Society for Neuroscience.

Livingston, B.P., T.R. Nichols (2005) Kinematic and EMG analysis of feline forelimb during the swing phase of slope walking and visually guided reaching. Washington, Society for Neuroscience (online program No 989.12).

Maas, H., R. Gregor, E.F. Hodson-Tole, B.J. Farrell, B.I. Prilutsky (2009) Distinct muscle fascicle length changes in feline medial gastrocnemius and soleus muscles during slope walking J Appl Physiol 106: 1169-1180.

Maas, H., B.I. Prilutsky, T.R. Nichols, R.J. Gregor (2007) The effects of self-reinnervation of cat medial and lateral gastrocnemius muscles on hindlimb kinematics in slope walking. Exp Brain Res 181: 377-393.

Manter, J.T. (1938) The dynamics of quadrupedal walking. J Exp Biol 15: 522-540.

Miller, S., F. Van Der Meché (1975) Movements of the forelimbs of the cat during stepping on a treadmill. Brain Res 91: 255-269.
Misiaszek, J.E., K.G. Pearson (2002) Adaptive changes in locomotor activity following botulinum toxin injection in ankle extensor muscles of cats. J Neurophysiol 87: 229-239.

Nichols, T.R. (1987) A technique for measuring the mechanical actions of heterogenic (intermuscular) reflexes in the decerebrate cat. J Neurosci Methods 21: 265-73.

Nichols, T.R. (1989) The organization of heterogenic reflexes among muscles crossing the ankle joint in the decerebrate cat. J Physiol 410: 463-477.

Nichols, T.R. (1999) Receptor mechanisms underlying heterogenic reflexes among the triceps surae muscles of the cat. J Neurophysiol 81: $467-478$

-Nichols, T.R. (2002) Musculoskeletal mechanics: a foundation of motor physiology. Adv Exp Med Biol 508: 473-479.

Nichols, T.R., J.C. Houk (1976) Improvement in linearity and regulation of stiffness that results from actions of stretch reflex. J Neurophysiol 39: 119-142.

-Pandy, M., V. Kumar, N. Berme, K. Waldron (1988) The dynamics of quadrupedal locomotion. J Biomech Eng 110: 230-237.

Pearson, K.G., K. Fouad, J.E. Misiaszek (1999) Adaptive changes in motor activity associated with functional recovery following muscle denervation in walking cats. J Neurophysiol 82: 370-381.

Philippson, M. (1905) L'autonomie et la centralisation dans le système nerveux des animaux. Bruxelles, Falk.

Prilutsky, B.I., M.G. Sirota, R.J. Gregor, I.N. Beloozerova (2005) Quantification of motor cortex activity and full-body biomechanics during unconstrained locomotion. J Neurophysiol 94: 2959-2969.

Ross, K.T., T.R. Nichols (2009) Heterogenic feedback between hindlimb extensors in the spontaneously locomoting premammillary cat. J Neurophysiol 101: 184-197.

Rossignol, S. (1996) Handbook of Physiology. New York, American Physiological Society.

Sanes, J.R., J.W. Lichtman (1999) Development of the vertebrate neuromuscular junction. Annu Rev Neurosci 22: 389.

Sherrington, C.S. (1906) Observations on the scratch-reflex in the spinal dog. J Physiol 34: $1-50$.

Simon, S.R., R.A. Mann, J.L. Hagy, L.J. Larsen (1978) Role of the posterior calf muscles in normal gait. J Bone Joint Surg Am 60: 465-472.

Smith, J., S. Chung, R. Zernicke (1993) Gait-related motor patterns and hindlimb kinetics for the cat trot and gallop. Exp Brain Res 94: 308322 .

Stein, R., J. Misiaszek, K. Pearson (2000) Functional role of muscle reflexes for force generation in the decerebrate walking cat. J Physiol 525: 781-791.

Walmsley, B., J.A. Hodgson, R.E. Burke (1978) Forces produced by medial gastrocnemius and soleus muscles during locomotion in freely moving cats. J Neurophysiol 41: 12031216. 